\title{
AVALIAÇÃO DA PRODUÇÃO DE ETANOL E COGERAÇÃO DE ENERGIA PELA CULTURA DO SORGO SACARINO
}

\author{
NÓBILE, Fábio Olivieri de. Professor Doutor do Centro Universitário da Fundação Educacional de \\ Barretos, SP - Unifeb. E-mail: fonobile@ feb.br. \\ NUNES, Hugo Dias. Graduando do Centro Universitário da Fundação Educacional de Barretos, SP - \\ Unifeb. E-mail: hugooguh_dn@ @otmail.com.
}

\begin{abstract}
RESUMO
A escassez de combustíveis fósseis e poluição ambiental fazem com que sejam discutidos novos biocombustíveis. Com isso, buscam-se novas fontes de combustíveis renováveis e uma alternativa na produção de etanol, além da cana-de-açúcar, é o sorgo sacarino, utilizando-o como um complemento, não como concorrente da cana-de-açúcar, já que a demanda por bicombustíveis cresce em grande escala mundialmente. O objetivo foi analisar a produção de etanol e cogeração de energia do sorgo sacarino na entressafra de canade-açúcar, e comparar o rendimento do sorgo sacarino com a cana-de-açúcar, os processos para obtenção e fabricação do etanol do sorgo sacarino e custo de produção, suprindo a falta de matéria prima na entressafra e aumentando o período de moagem nas usinas. A metodologia utilizada foi a pesquisa bibliográfica em periódicos científicos, livros e internet. Em um futuro próximo, com pesquisas em novas variedades mais produtivas, o sorgo sacarino surge como uma alternativa para se produzir etanol durante a entressafra da cana-de-açúcar pelo seu curto ciclo de semeadura e colheita, além dos fatores climáticos que favorecem seu desenvolvimento e aproveitamento dos mesmos sistemas utilizados para produção de etanol de cana-de-açúcar.
\end{abstract}

Palavras-chave: Sorgo sacarino; Biocombustíveis; Etanol.

\section{EVALUATION OF ETHANOL PRODUCTION AND COGENERATION OF ENERGY BY SWEET SORGHUM CULTURE}

\begin{abstract}
The scarcity of fossil fuels and environmental pollution have led to the discussions of new biofuels. For this reason new sources of renewable fuels are sought and an alternative to ethanol production, besides sugar cane, is sweet sorghum, using it as a complement, not as a competitor of sugar cane, considering that the demand for biofuels is growing on a large scale worldwide. The aim was to analyze the production of ethanol and the cogeneration of sweet sorghum in the offseason of sugar cane, and to compare the yield of sweet sorghum with sugar cane, the processes to obtain and to produce etnhanol from sweet sorgo and the production cost, supplying the lack of raw materials in the offseason and increasing the period of grinding mill. The methodology used was a bibliographical review in scientific journals, books and internet. In a near future, with research of new more productive varieties, sweet sorghum is an alternative to produce ethanol during the offseason of sugar cane for its short cycle of sowing and harvesting, besides climatic factors which favor its development and utilization of the same systems used for the production of ethanol from sugar cane.
\end{abstract}

KEYwORDs: Sweet sorghum; Biofuels; Ethanol. 


\section{INTRODUÇÃO}

O sorgo é o quinto cereal mais importante no mundo, sendo precedido pelo trigo, arroz, milho e cevada. Os grãos têm uso na alimentação humana, industrial, álcool, forragem ou cobertura de solo (SANTOS; TARDIN, 2007).

A energia renovável é uma fonte fundamental de energia, que contribui para a segurança energética, reduzindo a dependência dos combustíveis fósseis e as emissões de gases de efeito estufa. Nesse contexto, o sorgo sacarino se torna uma cultura de interesse, pois apresenta resistência a pragas, doenças e estresses hídricos, pode ser cultivada em terras marginais e fornecer alimentos e energia em um sistema alimentar e energético integrada (VINUTHA et al., 2014).

De acordo com Embrapa (2010), o sorgo é utilizado como principal fonte de alimento em grande parte dos países da África, Sul da Ásia e América Central, e importante componente da alimentação animal nos Estados Unidos, Austrália e América do Sul. Os grãos, também, podem ser utilizados na produção de farinha para panificação, amido industrial, etanol e a palhada como forragem e/ou cobertura de solo.

O sorgo é uma planta de metabolismo $\mathrm{C}_{4}$, de dias curtos e com altas taxas fotossintéticas, considerado uma "smart crop", em função de produzir combustível através da biomassa e açúcares fermentáveis que, industrializados, se transformam em etanol e/ou em alimento. Em se tratando de uma cultura de ciclo vegetativo curto, de 90 a 130 dias, apresenta-se ideal para o complemento na produção de etanol durante o período de entressafra da cana-de-açúcar, quando ainda se encontra em estado de desenvolvimento vegetativo e possui pouca concentração de açúcares, permitindo ampliar o período de uso das usinas de etanol em três meses. Ele também pode ser adequado em um sistema integrado de exploração da propriedade rural, objetivando à autossuficiência de energia, aliada a outras atividades voltadas para a produção agropecuária (SOUZA et al., 2005).

Destacam-se a cana-de-açúcar, a beterraba açucareira e o sorgo sacarino como as três culturas de grande potencial energético, como fontes renováveis de energia (LIPINSKI; KRESOVICH, 1982).

No Brasil, as zonas de adaptação da cultura se concentram no Sul (região de fronteira), em plantios de verão; no Brasil Central, em sucessão a plantios de verão (safrinha); e, no Nordeste, em plantios nas condições do semiárido, com altas temperaturas e precipitação inferior a $600 \mathrm{~mm}$ anuais. É uma cultura com custo significativamente mais baixo quando comparado ao do milho, com poucos problemas de pragas e doenças, e é muito tolerante à condição de estresse hídrico (LIMA, 2012).

A planta, que é fonte de etanol e açúcar, fornece quantidade de bagaço suficiente para geração de vapor para a operação industrial. Entretanto, difere da planta de cana-de-açúcar, pelo fato de ser cultivada a partir de sementes e apresentar um ciclo vegetativo mais curto, de 120 a 130 dias (CENBIO, 2012).

De acordo com Silva et al. (2007), o sorgo sacarino é um tipo de sorgo de porte alto, altura de planta superior a $2 \mathrm{~m}$ caracterizado, principalmente, por apresentar colmo doce e suculento, como o da canade-açúcar. A panícula é aberta e produz poucos grãos (sementes). Emalgumas regiões é utilizado como sorgo forrageiro, na forma de silageme de corte. Toda cultivar de sorgo sacarino pode ser utilizada como forrageira. Outra utilização a ser estudada é como matéria-prima para bioenergia (etanol).

O sorgo é uma planta da família gramineae, do gênero sorghum e da espécie Sorghum bicolor $L$. Moench. Sua estrutura radicular é composta por raízes que, por possuir sílica na endoderme, grande quantidade de pelos absorventes e altos índices de lignificação de periciclo, conferem à cultura maior tolerância a seca do que as demais. $\mathrm{O}$ caule, por sua vez, é dividido em nós e entrenós e folhas ao longo de toda a planta; sua inflorescência é uma panícula e seu fruto, uma cariopse ou grão seco (CERES, 2012).

O objetivo deste trabalho foi analisar a produção de etanol e cogeração de energia do sorgo sacarino na entressafra de cana-de-açúcar, e comparar o rendimento do sorgo sacarino com a cana-de-açúcar, os processos para obtenção e fabricação do etanol 
do sorgo sacarino e o custo de produção.

\section{Metodologia}

Foi realizada pesquisa bibliográfica fundamentada no sorgo sacarino: conceito, tipos e produtividade, para estimar a eficiência de produção de etanol e cogeração de energia, através do sorgo sacarino e do seu resíduo, como complementação a cana-de-açúcar.

Foi feita revisão bibliográfica em periódicos científicos, livros, internet, entre outros. Foram realizados comparativos do sorgo sacarino com a canade-açúcar.

\section{Fatores que afetam o desenvolvimento do sorgo sacarino}

O sorgo (Sorghum bicolor L. Moench) é nativo da África e algumas variedades atuais são originárias do continente africano. Iniciativas de introdução dessa gramínea no Brasil foram realizadas em eras diferentes, mas contam com esforços de institutos de pesquisa e universidades, sobretudo a partir da década de 1950. A Embrapa iniciou um programa de melhoramento de sorgo em meados da década de 1970, acreditando no potencial dessa cultura no país, e hoje a área plantada de sorgo no Brasilé de aproximadamente 1,5 milhão de hectares (PURCINO, 2011).

O desenvolvimento da cultura do sorgo no Brasil ocorre prioritariamente nas Regiões Sudeste, Sul e Centro-Oeste. Devido a sua característica intrínseca de maior tolerância ao déficit hídrico, tem potencialidade para o cultivo na região Nordeste, onde atualmente é cultivado principalmente por pequenos produtores, em sistema consorciado. Na região, a Bahia é o maior produtor, com 75,7 toneladas por hectare, e Pernambuco ocupa a segunda posição, com 10,7 toneladas por hectare de acordo com dados oficiais fornecidos pela Companhia Nacional de Abastecimento (CONAB 2009). Um grande aumento foi observado na produção dessa cultura no Brasil desde a sua provável consolidação como lavoura, em 1976, até os dias atuais.

Comparado com outros cereais, o sorgo requer menos água para se desenvolver, e seu período mais crítico à falta de água é o florescimento. Segundo Santos et al. (1996), a planta de sorgo se adapta a vários ambientes, principalmente a condições hídricas desfavoráveis, e, portanto, a cultura está apta a se desenvolver em regiões em que a distribuição de chuvas é irregular.

Adicionalmente, os setores de pesquisa e produtivos buscam alternativas para questões de maior uso e eficiência dos recursos da natureza, incluindo os fatores clássicos de produção - terra, capital e trabalho - e os itens modernos de competitividade - inovação, insumos modernos como agroquímicos fertilizantes e protetivos, biofertilizantes, economia de água, economia de carbono, oportunidade social de uso dos recursos, viabilidade econômico-financeira e empresarial, etc. (DURÃES, 2011).

Por ser de origem tropical, o sorgo é sensível a baixas temperaturas noturnas. A temperatura ótima para crescimento está por volta de $33-34^{\circ} \mathrm{C}$. Acima de $38^{\circ} \mathrm{C}$ e abaixo de $16^{\circ} \mathrm{C}$, a produtividade decresce. Baixas temperaturas causam redução na área foliar, perfilhamento, altura, acumulação de matéria seca e um atraso na data de floração. Isso acontece em razão de uma redução da síntese de clorofila, especialmente nas folhas, que se formam primeiro na planta jovem, com consequente redução da fotossíntese. Temperaturas mais altas geralmente tendem a antecipar a antese, assim como pode causar aborto floral. A temperatura baixa afeta o desenvolvimento da panícula, principalmente por seu efeito sobre a esterilidade das espiguetas. A sensibilidade a temperaturas baixas é maior durante a meiose (EMBRAPA, 2009).

São poucos os trabalhos relacionados com o manejo cultural do sorgo sacarino. Entretanto, ressaltam-se alguns trabalhos, como de Cowley \& Smith (1972), no qual se verificou que os rendimentos obtidos na cultura do sorgo sacarino são diretamente influenciados pelo comprimento dos dias de radiação solar global. Os melhores rendimentos em açúcares por área de cultivo estão estreitamente relacionados com dias mais longos e radiação solar máxima.

O produtor deve estar atento a ocorrências de pragas e doenças desde o plantio até a colheita. Várias 
espécies de pragas e patógenos podem estar associadas à cultura; entretanto, apenas algumas são expressivas e somente poucas causam dano econômico. Desse modo, é importante visitar periodicamente a lavoura para identificar as espécies que são nocivas e adotar medidas de controle quando necessário, pois a ocorrência da praga na lavoura nem sempre se relaciona ao nível de dano econômico e, viabilizando o nível mínimo de controle, esse fator varia com a população (COELHO et al., 2002).

Entre as pragas mais comuns, as de solo são as lagartas elasmo, lagarta rosca e as formigas. Já na parte aérea destacamos a Lagarta do cartucho (Spodoptera frugiperda). Existem duas espécies de pulgão que atacam o sorgo: o pulgão do milho (Rhopalosiphum maidis) e o pulgão verde ou o pulgão do trigo (Schizaphis graminum). O pulgão verde apresenta maior importância econômica que o pulgão do milho. As moscas do sorgo são pequenas, de coloração alaranjada e asas transparentes, medindo cerca de 2 $\mathrm{mm}$. Seus ovos são colocados no interior das flores, e as larvas resultantes se alimentam dos grãos do sorgo em formação; em consequência, as panículas ficam chochas e a queda na produção poderá ser significativa (LIRA JUNIOR, 2010).

As principais doenças do sorgo no Brasil, de significado econômico, são a podridão das sementes e doenças das plântulas, que podem afetar a germinação, o desenvolvimento inicial e reduzir o stand. Doenças foliares como Antracnose, Ferrugem, Vírus do mosaico da cana-de-açúcar e míldio têm grande importância para a cultura. Também podem aparecer doenças do colmo, como a podridão de Macrophomina e a podridão vermelha do colmo (EMBRAPA, 2010).

O problema com plantas daninhas está na sua interferência na capacidade que a cultura tem de se desenvolver de maneira sadia e vigorosa. Pode-se dizer que, quanto maior for o período de convivência das plantas daninhas com a cultura, maiores serão os danos causados por ela. Isso dependerá do ciclo da cultura e da época em que a mesma foi implantada. É mais comumente estudado o período a partir do plantio ou da emergência, emque a cultura deve ser mantida livre da presença da comunidade infestante, para que as produções não sejam afetadas, quantitativa e/ou qualitativamente. Na prática, esse deve ser o período em que as capinas ou o poder residual do herbicida devem cobrir. É interessante esclarecer o significado desse período em termos de interferência: as espécies daninhas que emergirem nesse período, em determinada época do ciclo da cultura, terão atingido tal estado de desenvolvimento que promoverão uma interferência sobre a planta cultivada, capaz de reduzir significativamente sua produtividade econômica. $\mathrm{O}$ período em que a lavoura necessita ficar mantida livre da infestação de invasoras, sob ameaça de comprometimento da produtividade, é conhecido como Período Crítico de Prevenção à Interferência - PCPI. Essa determinação do período crítico pode ser feita considerando-se os estados fenológicos dos genótipos ou em períodos de tempo. Para o sorgo, o estado fenológico da cultura é normalmente adotado, pois o número de dias após a emergência é variável em função de uma série de fatores, tanto biótico como abióticos (LARCHER, 2000).

\section{Extração do caldo e obtenção do bagaço de sorgo sacarino}

O sorgo sacarino como matéria-prima para produção de etanol oferece as vantagens de ser uma planta tolerante a déficit hídrico, ciclo curto, mecanizada, possui colmos suculentos com açúcares totalmente fermentáveis e com produção de massa verde variando de 40 a $60 \mathrm{t} \mathrm{ha}^{-1}$. O bagaço gerado pela extração do caldo serve também como fonte de energia para a indústria e geração de eletricidade, bem como permite a produção de etanol de segunda geração, e também como fonte de alimentação animal (OLIVEIRA; RAMALHO, 2006; LOURENÇO et al., 2010).

O teor de fibra do sorgo pode variar de acordo com as condições climáticas e agronômicas. Assim como a cana-de-açúcar, pequenos ajustes na moenda e embebição podem ser necessários para que se evitem problemas de embuchamento e se garanta alta eficiência 
de extração e umidade ideal do bagaço. Para a extração do bagaço de sorgo sacarino, o volume de água de embebição utilizado também foi variável, mas se estabeleceu, em média, em 30-40\% do volume do caldo. A concentração de açúcares no bagaço, caso a moenda opere em condição otimizada, mantém-se em aproximadamente $2 \%$. Nessas condições, obteve-se bagaço final com umidade de 50 a $52 \%$ e poder calorífico da ordem de $2.000 \mathrm{kcal} / \mathrm{kg}$, valores comparáveis ao bagaço de cana-de-açúcar (EMBRAPA Milho e Sorgo, 2012).

Problemas operacionais na moagem diminuem a eficiência de extração, aumentam a umidade do bagaço final, dificultando sua queima, e elevam a concentração de açúcares no bagaço, aumentando as perdas. Observa-se, no processamento industrial do sorgo, perdas de até $10 \%$ por problemas na operação de extração (MAGALHÃES, 2000).

\section{Tratamento, decantação e fermentação do caldo}

As etapas de tratamento e decantação do caldo seguem o mesmo padrão do processamento da canade-açúcar. Em alguns casos, pode-se observar necessidade de maior dosagem de substâncias floculantes e maior volume de lodo. O processamento industrial do sorgo sacarino apresentou teores de açúcar na torta de 1 a $3 \%$. Seu processamento no início da safra 2012/2013 apresentou concentração média de açúcar no mosto de $12 \%$, com leve aumento do consumo de vapor (DURÃES, 2011).

Nos processos industriais do sorgo sacarino, o uso de antibióticos foi feito apenas no início da propagação do fermento, assim como na cana-de-açúcar. O teor de açúcares redutores do sorgo sacarino é pouco maior do que o da cana-de-açúcar; entretanto, este fato não representou prejuízo nemocasionou contaminações nas fermentações. Sob condições normais, as células contaminantes mantiveram-se em concentração máxima de 106 células/ml. As leveduras se mostraram adaptadas ao mosto do sorgo sacarino, garantindo baixa concentração residual de açúcar nas dornas. $\mathrm{O}$ teor de amido nas dornas manteve-se em aproximadamente 3 a $4 \mathrm{~g} / \mathrm{l}$, não interferindo no processo produtivo (PURCINO, 2011).

De acordo com Cao et al. (2014), a préfermentação do caldo de cana e mosto misturado com grãos de sorgo diminuiu o tempo de fermentação e melhorou a eficiência do etanol em comparação com o controle. Sob as condições experimentais, a concentração máxima de etanol foi de $65,64 \pm 0,57 \mathrm{~g}$ $\mathrm{L}^{-1}$; a produtividade de etanol, de 5,47 $\pm 0,04 \mathrm{~g} \mathrm{~L}^{-1}$; e a eficiência do rendimento, de $89,29 \pm 0,77 \%$, a partir do suco de $80 \%$ do volume da fração do mosto de grãos de sorgo clarificado - respectivamente 6,8, 33,5, e $13,7 \%$ mais elevadas do que as aferidas no caldo de sorgo sozinho.

Khongsay et al. (2014), avaliando a fermentação redox controle potencial (sem controle, $-100 \mathrm{mV}$ e $150 \mathrm{mV}$ ) na melhoria da produtividade do etanol, durante alta gravidade (VHG) da fermentação do caldo de sorgo sacarino (300 g/L de açúcar total), observaram que o potencial redox em $-150 \mathrm{mV}$ deu as maiores eficiências de produção de etanol (concentração de etanol de 134,35 $\pm 1,67 \mathrm{~g}$ de etanol/ L e produtividade de etanolde 2,80 $\pm 0,03 \mathrm{~g} / \mathrm{L}$ etanol) na fermentação tempo de 48 horas. Sob as mesmas condições e sem tratamento redox, a eficiência e a concentração de etanol foram 115,34 $\pm 2,01 \mathrm{~g} / \mathrm{L}$ e de $2,14 \pm 0,05 \mathrm{~g} / \mathrm{L}$, respectivamente, no tempo de fermentação de 54 horas.

\section{Subprodutos}

Além do etanol e do gás carbônico, são formados, em fermentações alcoólicas, outros subprodutos em quantidade dependente do estresse causado às leveduras, geralmente por contaminação bacteriana, altas temperaturas, carência ou excesso de nutrientes e tratamento ácido incorreto. Os níveis de formação de subprodutos observados são semelhantes aos do caldo de cana-de-açúcar, e estão relacionados a diversos parâmetros de condução da fermentação. A fermentação do sorgo sacarino, se conduzida em condições similares ao processamento da cana-deaçúcar, apresenta formação de subprodutos semelhantes (EMBRAPA Milho e Sorgo, 2012).

A produção de etanol anidro e hidratado dentro da 
especificação depende da operação eficiente da destilação, não se relacionando com a matéria-prima, neste caso. Se o sistema de destilação operar em condições ótimas, as perdas de etanol na vinhaça e na flegmaça podem ser consideradas desprezíveis, semelhantes às perdas associadas à cana-de-açúcar. Para o processamento da cana-de-açúcar, a vinhaça, resíduo rico em minerais e com alta carga orgânica, após resfriada, é utilizada na lavoura como fertilizante. Não se tem conhecimento de análises do desempenho da fertirrigação com vinhaça de sorgo sacarino. Sua aplicação deve ser ajustada para atendimento da norma que fixa a dosagem de vinhaça no solo (EMBRAPA Milho e Sorgo, 2012).

Marx et al. (2013), estudando a utilização do bagaço do sorgo sacarino doce (rico em lignocelulose), observaram que o açúcar pode ser convertido em uma única etapa usando irradiação de micro-ondas, considerando que o bagaço do sorgo sacarino doce passou por pré-tratamento e hidrolisação. Com isso, observaram que a produção total de açúcar de $820 \mathrm{~g} \mathrm{~kg}^{-1}$ foi obtida em uma solução de ácido sulfúrico $5 \%$ em água. Um rendimento de etanol à base de açúcar total de $480 \mathrm{~g}$ $\mathrm{kg}^{-1}$ foi obtido após 24 horas de fermentação, utilizando uma cultura mista de organismos. Esses resultados mostram o potencial para produzir $33 \mathrm{~m}^{3}$ $\mathrm{ha}^{-1}$ de etanol usando apenas a parte de lignocelulose dos caules, que é suficiente para tornar o processo economicamente atraente.

\section{Custos de produção de etanol através do sorgo sacarino}

Devido à semelhança com a cana-de-açúcar e o alto teor de açúcar fermentescível, a produção de etanol a partir do sorgo sacarino é considerável viável além do processamento que pode ser feito nas usinas de cana-de-açúcar. Um ponto importante é a produção de etanol no período de entressafra de cana-de-açúcar. O potencial mínimo de geração de etanol de sorgo sacarino está estimado em $3.223 \mathrm{~L} / \mathrm{ha}$, com uma produtividade que gira em torno de $55 \mathrm{t} / \mathrm{ha}$, o que representa cerca de 58,6 L/t. As estimativas no país sobre o processamento em escala industrial do etanol, a partir do sorgo sacarino, é de mais difícil acesso, estando limitadas às empresas produtoras, que somente recentemente deram margem a essa iniciativa. Segue a Tabela $1 \mathrm{com}$ as estimativas de custos da produção de etanol a partir do sorgo sacarino (LIMA et al., 2011).

Tabela 1 - Estimativas dos custos de produção de etanol a partir do sorgo sacarino.

\begin{tabular}{lc}
\hline Descrição & Preço Unitário (R $\$ / L i t r o)$ \\
\hline Fator de Conversão de sorgo em etanol $\left(0,03505 \mathrm{~m}^{3} / \mathrm{t}\right)$ & \\
Custo da matéria prima & $\mathrm{R} \$ 0,48$ \\
Custo fixo/L & $\mathrm{R} \$ 0,17$ \\
Custo de processamento/L & $\mathrm{R} \$ 0,34$ \\
Custo Total & $\mathrm{R} \$ 0,99$ \\
\hline
\end{tabular}

Fonte: LIMA et al. (2011).

Os custos de produção agrícola do sorgo em janeiro de 2011 estiveram em torno de R \$ 927/ha. Entretanto, para estimar o custo total de produção em termos de $\mathrm{R} \$ / \mathrm{L}$, seria necessário transformar este valor por meio do fator de conversão do substrato em etanol.
Utiliza-se um fator de conversão de $0,03505 \mathrm{~m} / \mathrm{t}$, ou seja, cada tonelada de biomassa verde de sorgo geraria 35,05 litros de etanol. Multiplicando-se esse fator pela produtividade por hectare do sorgo (55 t/ha), tem-se um total de $1.920 \mathrm{~L} / \mathrm{ha}$. Assim, poderia afirmar-se que 
o custo unitário da matéria-prima estaria em torno de $\mathrm{R} \$ 0,48 / \mathrm{L}$, sem incluir quaisquer custos de transporte (LINTON et al., 2011).

Por outro lado, com base no trabalho de Linton et al. (2011), estima-se que os custos fixos unitários seriam de $\mathrm{R} \$ 0,17 / \mathrm{L}$ e os custos de processamento, $\mathrm{R}$ \$ 0,34/litro. Desse modo, tendo em vista os parâmetros aqui adotados, o custo total de produção de etanol do sorgo sacarino seria de aproximadamente $\mathrm{R} \$ 0,99 / \mathrm{L}$.

\section{Produção de etanol sorgo sacarino $x$ cana-de- açúcar}

De acordo com Emydio (2010), as vantagens comparativas do sorgo sacarino com a cana-de-açúcar é que o ciclo da cultura do sorgo sacarino é de quatro a quatro meses e meio, e o da cana-de-açúcar é de nove a dezoito meses. A quantidade necessária de água para o sorgo é de $9000 \mathrm{~m}^{3}$, e para a cana-de-açúcar, $36000 \mathrm{~m}^{3}$.

O custo estimado para cana-de-açúcar entre os produtores brasileiros é de $\mathrm{R} \$ 0,90$ o litro e o sorgo sacarino, $R$ \$ 0,99. A vantagem da cana-de-açúcar e sorgo é que a molécula de açúcar (sacarose), que tem o etanol como subproduto, é facilmente quebrada pelas enzimas, pulando uma etapa na fabricação do etanol. O sorgo e a cana-de-açúcar podem ser colhidos o ano todo, e a cana-de-açúcar precisa ser replantada num período de, em média, 5 a 6 anos. O lado ruim é que, quando se colhe a cana-de-açúcar, tem que ser moída em menos de 36 horas, pois sua fermentação leva de 7 a 11 horas, já que as moléculas de açúcar são menores e mais fáceis de serem quebradas. A produtividade ainda é o diferencial entre cana-deaçúcar e sorgo. Parâmetros como Brix e porcentagem de fibra servem para avaliação de rendimento, seja este rendimento o lucro para o produtor ou rendimento de matéria verde da cultura (Tabela 2). Enquanto a cana-de-açúcar rende em média de 75 t/ha, o sorgo rende em média 55 t/ha. Portanto, a produção de etanol através do sorgo sacarino é de $3.223 \mathrm{~L} / \mathrm{ha}$, o que representa cerca de 58,6 L/t, enquanto o etanol de cana-de-açúcar gera, em média, 7.000 L/ha, o que representa cerca de 93,3 L/t (REVISTA SUPER INTERESSANTE, 2007).

A Tabela 2 mostra valores médios dos principais parâmetros de interesse industrial entre o sorgo sacarino e a cana-de-açúcar.

Tabela 2 - Comparativos técnicos cana-de-açúcar x sorgo sacarino.

\begin{tabular}{lcc}
\hline PARÂMETRO & $\begin{array}{c}\text { SORGO } \\
\text { SACARINO }\end{array}$ & $\begin{array}{c}\text { CANA-DE- } \\
\text { AÇÚCAR }\end{array}$ \\
\hline Brix caldo & $15-19$ & $18-25$ \\
Pureza & $60-75$ & $80-90$ \\
Fibra (\%) & $12-20$ & $10-15$ \\
Sacarose caldo (\%) & $8-13$ & $14-22$ \\
AR (Açúcares Redutores) caldo (\%) & $1-3$ & $0,5-1$ \\
Glicose caldo (\%) & $0,5-2$ & $0,2-1$ \\
Frutose caldo (\%) & $0,5-1,5$ & $0-0,5$ \\
ART (Açúcares Redutores Totais caldo (\%) & $12-17$ & $15-24$ \\
Amido caldo (\%) & $0,1-0,5$ & $0,001-0,05$ \\
\hline
\end{tabular}

Fonte: EMBRAPAMilho e Sorgo, 2012. Com adaptações. 
Sobre a composição do bagaço do sorgo sacarino e da cana-de-açúcar, o valor de lignina do sorgo sacarino representa $11,90 \%$ e o da cana-de-açúcar, $20,50 \%$; a penstosana do sorgo sacarino representa $26,90 \%$ e a da cana-de-açúcar, $26,35 \%$; e a celulose do sorgo sacarino representa $46,57 \%$ e a da canade-açúcar, 47,70\% (SANTOS, 2007).

\section{Metas e rendimentos do sorgo sacarino}

Pelo menos uma dezena de usinas já está fazendo testes significativos com variedades de sorgo com áreas plantadas que variam de 300 a 500 hectares, para validar a matéria-prima para produção de etanol e energia elétrica nos períodos de entressafra (BURNIQUIST, 2012). Diferentes variedades apresentam uma enorme variação na sua composição em diferentes localidades. É importante saber qual variedade vai ser plantada, fazer uma pré-análise para saber sua composição química e inserir as leveduras mais adaptadas (AMORIM, 2012).

No início dos anos de 1980, a Embrapa selecionou variedades de sorgo sacarino com produtividade de 40 t/ha e teor de sólidos solúveis entre 18 e 20 de Brix. O Proálcool incentivou a cana-de-açúcar para produção de etanol; com isso, as plantas alternativas, entre elas o sorgo sacarino, tiveram seus programas paralisados. Como a planta apresentava boa produtividade e qualidade de matéria verde, se manteve no mercado, comercializado como forrageira. AEmbrapa reiniciou o programa em 2008, devido ao potencial de geração de bioenergia e à demanda de matéria-prima para produção de etanol (EMBRAPA, 2010).

O programa de melhoramento da Embrapa visa ao desenvolvimento de variedades e/ou híbridos de sorgo sacarino e estabeleceu as seguintes metas: produtividade mínima de biomassa de $60 \mathrm{t} / \mathrm{ha}$; produção mínima de etanol de 60 L/t; Período de Utilização Industrial (PUI) mínimo de 30 dias com extração mínima de açúcar total de $100 \mathrm{~kg} / \mathrm{t}$ biomassa.

\section{Conclusão}

Concluiu-se que, para a produção de etanol, o sorgo sacarino surge como alternativa na entressafra de canade-açúcar, aumentando o período de moagem das usinas e, consequentemente, a produção do biocombustível. A matéria-prima se depara com a dificuldade de implantação por parte dos usineiros, já que necessita de incentivos por parte do governo e ousadia para lançar novas mentalidades. O custo para se produzir etanol através do sorgo sacarino é favorável, pois a estrutura utilizada é praticamente a mesma do processo de cana-de-açúcar, com alterações mínimas em máquinas e equipamentos.

Há uma grande oportunidade, considerando pesquisas em novos híbridos, para se aumentar a produtividade ( $\mathrm{t} / \mathrm{ha}$ ) e a produção de etanol (L/ha) do sorgo sacarino, que é considerada inferior se comparada à da cana-de-açúcar. Verificou-se que, para a produção de energia através da biomassa, a quantidade de resíduos será maior, devido ao bagaço e à palha da planta, com teor de fibra de cerca de $11 \%$ a $15 \%$ em massa, em base seca, e poder calorífico de aproximadamente $15 \mathrm{MJ} / \mathrm{kg}$, e a sua similaridade de potencial energético com a cana-de-açúcar

Portanto, o sorgo sacarino passa a ser uma opção para a produção de etanol e energia elétrica, mas ainda é necessário o investimento em pesquisas de novas variedades, considerando o sorgo sacarino complementar ao período de entressafra da cana-deaçúcar; assim, o etanol e energia elétrica serão fornecidos por quase todo o ano.

\section{REFERÊNCIAS}

AMORIM, H. O canavial pede melhor tratamento. Revista Alcoolbrás, 2012, Ed. ${ }^{\circ}$ 134. Diponível em: < http:// www.revistaalcoolbras.com.br/edicoes/ed_134/ mc_1.html>. Acesso em: 23 mai. 2012.

BURNIQUIST W., AMORIM, H. O canavial pede melhor tratamento. Revista Alcoolbrás, 2012, Ed. n 134 . Disponível em: <http:// www.revistaalcoolbras.com.br/edicoes/ed_134/ mc_1.html>.Acesso em: 26 out. 2012. 
Avaliação da produção de etanol e cogeração...

CAO, W.; LIU, R.; SUN, C.; MEI, X. Cofermentation of Stalk Juice and Clarified Grain Mash of Sweet Sorghum for Ethanol Production. Energy Sources, v. 36, n. 8, p. 914-921, 2014.

CENBIO. Banco de Biomassa. Revista brasileira de Bioenergia. Disponível em: <http:// cenbio.iee.usp.br/saibamais/bancobiomassa/ vegetaisnaolenhosos/sacarideos.htm > Acesso em: 05 out. 2012.

COELHO, A. M.; Waquil, J.M; KARAM, D. Seja o Doutor do seu Sorgo, Sete lagoas-MG. 2002. Embrapa-Milho e Sorgo.

Companhia Nacional de Abastecimento - CONAB. Central de informações agropecuárias. Safras. Disponívelem: < http://www.conab.gov.br/ conabweb/index.php?PAG=101. 10> Acesso em: 26 out. 2012.

COWLEY, O. H.; SMITH, B. S. Sweet sorghum as a potencial sugar crop in south Texas. In:

CONGRESS OF THE INTERNATIONAL SOCIETY OF SUGAR CANE TECHNOLOGY, 14., 1971, New Orleans, Proceedings..., New Orleans: [s.n.], 1972. p. 628-633.

DURÃES, F. O. M. Agroenergia em Revista. 3 ed. Embrapa Agroenergia. v. 3. 52 p. 2011. Brasília.

EMBRAPA, 2010. Disponível em: <http:// www.cnpms.embrapa.br/grao/26_edicao/ grao_em_grao_materia_04.htm>.Acesso em: 28 ago. 2012.

EMBRAPA, 2000. Disponível em: <http:// sistemasdeproducao.cnptia.embrapa.br/ FontesHTML/Sorgo/CultivodoSorgo/index.htm>. Acesso em: 25 mar. 2012.

EMBRAPA, 2009. Disponível em < http:// www.cnpms.embrapa.br/noticias/mostranoticia- .php?codigo=593>. Acesso em 25 mar. 2012.

EMBRAPA Milho e Sorgo. Embrapa mostra potencial do sorgo durante evento sobre bioenergia. Sete Lagoas-MG. Ano 06. Ed.34. 2012.

EMYDIO, B. M. Produção de etanol a partir do sorgo sacarino. 2010. Artigo em Hypertexto. Disponível em:<http://www.infobibos.com/Artigos/ 2010 4/sorgo/index.htm>. Acesso em 11 mai. 2012.

KHONGSAY, Naulchan; LIN, Yen-Han; LAOPAIBOON, Pattana; LAOPAIBOON, Lakkana. Improvement of very-high-gravity ethanol fermentation from sweet sorghum juice by controlling fermentation redox potential. Journal of the Taiwan Institute of Chemical Engineers, v. 45, n. 2, p. 302-307, 2014.

LARCHER, W. Ecofisiologia vegetal. São Carlos: RIMA, 2000. $531 \mathrm{p}$.

LIMA, A. M. et al. Viabilidade econômica e arranjos produtivos. 2011. Disponível em: <http:// www.infoteca.cnptia.embrapa.br/bitstream/doc/ 903320/1/RevistaAgroenergia31429.pdf $>$. Acesso em: 02 jul. 2012.

LIMA, G. Produção de sorgo granífero no ceará. Conab, 2012. Disponível em: <http:// www.conab.gov.br/OlalaCMS/uploads/arquivos/ 12_04_10_13_43_12_conjuntur a_sorgo_granifero_em_graos_2012_ceara.pdf $>$. Acesso em: 18 jun. 2012.

LINTON, J. A. et al. Economic feasibility of producing sweet sorghum as an ethanol feedstock in the southeastern United States. Biomass and Bionergy, n. 35, p. 3050-57, 2011.

LIPINSKI, E.S.; KRESOVICH, S. Sugar crops as a solar energy converters. Experientia, v.38, p.137, 1982. 
LIRA JUNIOR., M. Produção de Sorgo Sorghum bicolor L. Moench Aspectos Gerais. 2010. Universidade Federal Rural de Pernambuco Programa de Pós Mestrado em Melhoramento Genético de Produção de Sorgo.

LOURENÇO, M. E. V.; MASSA, V. M. L.; PALMA, P. M. M.; RATO, A. E. M.

Potencialidades do sorgo sacarino [Sorghum bicolor (L.) Moench] para a produção sustentável de bioetanol no Alentejo. Revista de Ciências Agrárias, Belém, v. 30, n. 1, p. 103-110, 2010.

MAGALHÃES, P. C., DURÃES, F. O. M., SCHAFFERT, R. E. Fisiologia da planta de sorgo. Sete Lagoas, MG. Embrapa Milho e Sorgo, 2000. 46 p. (Embrapa Milho e Sorgo. Circular Técnica, 3).

MARX, S.; NDABA, B.; CHIYANZU, I.; SCHABORT, C. Fuel Ethanol Production from Sweet Sorghum Bagasse Using Microwave Irradiation. Biomass \& Bioenergy, Amsterdam, v. 59, p. 1-6, 2013.

OLIVEIRA, A. J.; RAMALHO, J. (Coord.). Plano Nacional de Agroenergia: 2006-2011. 2 ed. rev. Brasília, DF: Embrapa Informação Tecnológica, 2006. 110 p.

PURCINO, A. A. C. Sorgo Sacarino na Embrapa: histórico, importância e usos. Agroenergia em Revista. 3 ed. Embrapa Agroenergia. Brasília, v. 3. 52 p. 2011.

REVISTASUPER INTERESSANTE, 2007. Quais as diferenças entre o etanol de cana-de-açúcar e o de milho? Disponível em: <http://super.abril.com.br/ alimentacao/quais-diferencas-alcool-cana-milho- 446893.shtml>. Acesso em: 13 set. 2012.

SANTOS, F.G.; COSTA, E.F.; RODRIGUES, J.A.S.; LEITE, C.E.P.; SCHAFFERT, R.E. Avaliação do comportamento de genótipos de sorgo para resistência à seca. In: CONGRESSO NACIONAL DE MILHO E SORGO, 21., Londrina, 1996. Resumos... Londrina: IAPAR, 1996. p.32.

\section{SANTOS, F. G. Culturas com potencial para} produção de etanol. Simpósio Estadual de Agroenergia. Pelotas-RS. 2007.

SANTOS, F. G.; TARDIN, F. D. Cultivo do sorgo: cultivares. Sete Lagoas: Embrapa Milho e Sorgo, 2007. (Sistemas de Produção, 2). Disponível em: <http://sistemasdeproducao.cnptia.embrapa.br/ FontesHTML/Sorgo/CultivodoSorgo_3ed/ cultivares.htm>. Acesso em: 13 set. 2012.

SILVA, A. G. e.al. Avaliação Agronômica de cultivares de Sorgo Forrageiro no sudoeste do estado de Goiás em 2005. Revista Brasileira de Milho e Sorgo, v.6, n.1, p.116-127, 2007.

SOUZA, C. C.; DANTAS, J. P.; SILVA, S. M.; SOUZA, V. C.; ALMEIDA, F. A.; SILVA, L. E. Produtividade do Sorgo granífero cv. sacarino e qualidade de produtos formulados isoladamente ou combinados ao caldo de cana-de-açúcar. Ciência e Tecnologia de Alimento, Campinas, v. 25, n. 3, p. 512-517, 2005.

VINUTHA, K. S.; RAYAPROLU L.; YADAGIRI, K.; UMAKANTH, A. V.; PATIL, J. V.; RAO, P. S. Sweet Sorghum Research and Development in India: Status and Prospects. Sugar Tech, v. 16, n. 2, p. 133-143, 2014.

RECEBIDO EM 24/1/2014

ACEITO EM 5/6/2014 